Forthcoming in Steeves Demazeux and Patrick Singy (eds.), The DSM-5 in Perspective: Philosophical Reflections on the Psychiatric Babel. Dordrecht: Springer.

\title{
DSM-5 and Psychiatry's Second Revolution: Descriptive vs. Theoretical Approaches to Psychiatric Classification
}

\author{
Jonathan Y. Tsou \\ Department of Philosophy and Religious Studies, Iowa State University
}

\begin{abstract}
A large part of the controversy surrounding the publication of DSM-5 stems from the possibility of replacing the purely descriptive approach to classification favored by the DSM since 1980. This paper examines the question of how mental disorders should be classified, focusing on the issue of whether the DSM should adopt a purely descriptive or theoretical approach. I argue that the DSM should replace its purely descriptive approach with a theoretical approach that integrates causal information into the DSM's descriptive diagnostic categories. The paper proceeds in three sections. In the first section, I examine the goals (viz., guiding treatment, facilitating research, and improving communication) associated with the DSM's purely descriptive approach. In the second section, I suggest that the DSM's purely descriptive approach is best suited for improving communication among mental health professionals; however, theoretical approaches would be superior for purposes of treatment and research. In the third section, I outline steps required to move the DSM towards a hybrid system of classification that can accommodate the benefits of descriptive and theoretical approaches, and I discuss how the DSM's descriptive categories could be revised to incorporate theoretical information regarding the causes of disorders. I argue that the DSM should reconceive of its goals more narrowly such that it functions primarily as an epistemic hub that mediates among various contexts of use in which definitions of mental disorders appear. My analysis emphasizes the importance of pluralism as a methodological means for avoiding theoretical dogmatism and ensuring that the DSM is a reflexive and self-correcting manual.
\end{abstract}

KEYWORDS: Diagnostic and Statistical Manual of Mental Disorders; psychiatric classification; natural kinds in psychiatry; validity of diagnostic categories; scientific pluralism 


\section{Introduction}

The question of whether mental disorders should be classified in a theoretical or purely descriptive manner is a philosophical issue embedded in the history of the Diagnostic and Statistical Manual of Mental Disorders (DSM). In the first two editions of the DSM (APA 1952, 1968), mental disorders were classified theoretically insofar as diagnostic categories reflected central distinctions of psychoanalysis (e.g., the distinction between neurosis and psychosis) and disorders were distinguished in terms of biological ('organic') and psychological ('functional') causes (see Tsou 2011). The publication of DSM-III (APA 1980) marked psychiatry’s first revolution in psychiatric classification insofar as the DSM-III taskforce, chaired by Robert L. Spitzer, self-consciously replaced the psychoanalytic and etiological approach to classification adopted in DSM-I and DSM-II with a purely descriptive (“neo-Kraepelinian”) approach that made no theoretical assumptions about the causes of mental disorders. ${ }^{1}$ The purely descriptive approach to classification championed by the DSM since DSM-III has recently been brought into question with the publication of DSM-5.

Prior to the publication of DSM-5, there were some indications that DSM-5 would mark psychiatry's second revolution in classification by ushering a paradigm shift away from the DSM’s purely descriptive approach. In particular, some reports from the DSM-5 taskforce, chaired by David J. Kupfer, indicated that DSM-5 would move the DSM away from the neoKraepelinian approach towards a theoretical and etiological approach to psychiatric classification informed by sciences such as genetics and neuroscience (e.g., see Kupfer, First, \& Regier 2002; Hyman 2007; Regier 2008; Regier, Narrow, Kuhl, \& Kupfer 2009; Kupfer \& Regier 2011; Kupfer, Kuhl, \& Regier 2013, p. E2). In articulating a research agenda for DSM-5, Kupfer, First, and Regier (2002) contend that:

[L]imitations in the current [neo-Kraepelinian] diagnostic paradigm suggest that research exclusively focused on refining the DSM-defined syndromes may never be successful in uncovering their underlying etiologies. For that to happen, an as yet unknown paradigm shift may need to occur. . . [An] important goal . . . is to transcend the limitations of the current DSM paradigm and to encourage a research agenda that goes beyond our

\footnotetext{
${ }^{1}$ For a more comprehensive discussion of the neo-Kraepelinian outlook of DSM-III, see Klerman (1978), Blashfield (1984), Wilson (1993), Compton \& Guze (1995), Mayes \& Horwitz (2005), Decker (2007, 2013), and Tsou (2011).
} 
current ways of thinking to attempt to integrate information from a wide variety of sources and technologies. (p. xix, emphasis added)

The publication of DSM-5 (APA 2013) would be disappointing to those who expected revisions of paradigm-shifting proportions. The main difference in DSM-5, compared to DSM-IV-TR (APA 2000), is the greater use of dimensional measures. Nonetheless, the recent publication of DSM-5 occasions a reconsideration of the prospects of theoretical versus purely descriptive approaches to psychiatric classification.

The aim of this paper is to critically evaluate the relative merits of purely descriptive and theoretical approaches to psychiatric classification for meeting the DSM's goals of providing a manual that can guide treatment, facilitate research, and improve communication. I argue that the DSM's purely descriptive approach is impoverished for meeting these aims and would benefit by shifting towards a theoretical system that integrated information about the causes of mental disorders into its descriptive categories. The paper proceeds as follows. In section 2, I discuss the aims associated with the purely descriptive approach to classification adopted since DSM-III. In section 3, I compare the relative benefits and costs of purely descriptive versus theoretical approaches for meeting these aims. I argue that descriptive approaches are best suited for coordinating communication among mental health professionals; however, theoretical approaches are better suited for meeting the DSM's goals of facilitating research and treatment. In section 4, I argue that the DSM should adopt a hybrid model that integrates the benefits of descriptive and theoretical approaches. In articulating this argument, I suggest that the DSM ought to narrow its goals, such that it functions primarily as an epistemic hub, i.e., a reference point that can mediate among the various contexts in which definitions of mental disorders appear (Kutschenko 2011). To be a useful epistemic hub, I suggest that the DSM should classify mental disorders that are natural kinds (i.e., kinds associated with a distinctive biological causal structure) and its diagnostic categories should be informed by the best available theories on the biological causes of mental disorders. With respect to how the DSM could integrate causal theories into its descriptive categories, my argument emphasizes the importance of pluralism as a means to ensure that the DSM is informed by a multiplicity of, sometimes conflicting, scientific theories on psychopathology. 


\section{Aims of the DSM}

The aims of the DSM are ambiguous and multifaceted because they have been historically shaped by a variety of social forces, such as the US healthcare system, the pharmaceutical industry, and various lobbyist groups (see Cooper 2005; Tsou 2011; Sadler 2013). In the late 1970s, when DSM-III was being drafted, psychiatry (i.e., psychoanalytically oriented psychiatry) was in a state of crisis and the American Psychiatric Association (APA) was facing pressure to revise the DSM so it would provide clear and reliable diagnostic categories for purposes of medical insurance reimbursement (Tsou 2011). Moreover, the emergence of pharmacological drugs (e.g., antipsychotic drugs) in the 1950s and 1960s that could treat the symptoms of more severe mental disorders created a need for reliable diagnostic categories to ensure that patients were properly diagnosed before receiving pharmacological treatment. DSM-III addressed these practical problems by providing a manual with clear and reliable diagnostic classifications and introducing the now familiar diagnostic criteria that demand that a set of operationalized necessary and sufficient criteria (mainly behavioral criteria) be satisfied for a diagnosis to be made.

In the introduction to DSM-III, the purely descriptive approach to classification is justified in terms of its capacity to facilitate widespread use of the manual by clinicians of diverse theoretical orientations:

The approach taken in DSM-III is atheoretical with regard to etiology . . . except for those disorders for which this is well established ... The major justification for the generally atheoretical approach ... is that the inclusion of etiological theories would be an obstacle to use of the manual by clinicians of varying theoretical orientations ... Because DSM-III is generally atheoretical with regard to etiology, it attempts to describe comprehensively what the manifestations of the mental disorders are, and only rarely attempts to account for how the disturbances come about ... This approach can be said to be "descriptive" in that the definitions of the disorders generally consist of descriptions of the clinical features of the disorders. . . . at the lowest order of inference necessary to describe the characteristic features of the disorder. (APA, 1980, p. 7, emphasis added) 
As alluded to in this passage, one of the chief motivations for adopting a descriptive and atheoretical approach was to remove speculative psychoanalytic theoretical assumptions that typified DSM-I and DSM-II. Consequently, the shift to a neo-Kraepelinian approach in DSM-III allowed mental health professionals with diverse theoretical orientations to utilize the DSM. In this regard, it is no accident that the DSM only became a highly influential, and increasingly entrenched, manual after 1980.

Besides permitting widespread usage of the manual, the DSM is presented as a manual that aims to guide treatment, facilitate research on mental disorders, and improve communication among mental health professionals. These goals are stated most explicitly in the introduction to DSM-IV-TR as follows:

Our highest priority has been to provide a helpful guide to clinical practice. We hoped to make DSM-IV practical and useful for clinicians by striving for brevity of criteria sets, clarity of language, and explicit statements of the constructs embodied in the diagnostic criteria. An additional goal was to facilitate research and improve communication among clinicians and researchers. (APA 2000, p. xxiii, emphasis added)

The purpose of DSM-IV is to provide clear descriptions of diagnostic categories in order to enable clinicians and investigators to diagnose, communicate about, study, and treat people with various disorders. (APA 2000, p. xxxvii, emphasis added)

As indicated here, the DSM aims to meet three primary goals: (1) to guide clinical treatment by providing operational definitions of mental disorders that allow clinicians to diagnose and make judgments about what treatment interventions are appropriate, (2) to facilitate research by providing standardized definitions that can be utilized in the study of mental disorders, and (3) to improve communication among mental health professionals presupposing disparate theoretical assumptions (cf. APA 2013, p. xli).

Despite its explicit articulation of its goals, the DSM is ambiguous in its intended aims, especially with respect to how — and to what extent—-the manual is intended to facilitate treatment and research. Moreover, I contend that the DSM's assumption that the various goals and uses of the DSM “are compatible with one another" (APA 2000, p. xxviii) is misleading (cf. 
Frances \& Widiger 2012, p. 110). My counter-suggestion is that there are tradeoffs between how well descriptive and theoretical manuals can facilitate these various goals.

\section{Descriptive vs. Theoretical Approaches to Psychiatric Classification}

Given that the aims of the DSM are to facilitate treatment, research, and communication, what are the prospects of purely descriptive versus theoretical approaches for achieving these goals? While the DSM's purely descriptive approach does well at facilitating communication and promoting the widespread use of the manual, I argue that a theoretical approach would provide a superior method for guiding treatment and research. My argument assumes that the DSM ought to classify mental disorders that are natural kinds (as opposed to artificial kinds).

\subsection{Descriptive Approaches}

The main virtue of purely descriptive approaches to classification is the facilitation of communication among mental health professionals. Purely descriptive approaches achieve this end by providing a system of standardized definitions of mental disorders, which can be utilized in a variety of contexts, including contexts of research and treatment. A related benefit of the DSM's neo-Kraepelinian approach is that its definitions can be widely used by mental health professionals working from a variety of theoretical orientations because the manual makes no metaphysical assumptions about the causes of mental disorders. Hence, the main benefits of purely descriptive approaches stem from the provision of a common language for communicating about mental disorders and the potential of its descriptive categories to be widely used.

While the DSM does well at facilitating communication and widespread usage, its purely descriptive approach is only minimally useful for research and treatment. With respect to research, the main disadvantage of the DSM's descriptive and atheoretical approach is the difficulty of testing its diagnostic categories. Since mental disorders are defined behaviorally, there is no principled way of determining whether a diagnostic category merits inclusion or exclusion in the manual. Moreover, although the authors of the DSM claim that the primary 
purpose of the DSM is to guide treatment, the DSM's fine-grained diagnostic categories are only minimally useful for guiding treatment decisions. For purposes of treatment, clinicians may find some use in broad DSM categories that distinguish depression from anxiety and psychosis; however, beyond these broad classificatory distinctions, DSM classifications do little to guide treatment interventions that go beyond clinicians’ tacit knowledge (Brown 1987; Kirk \& Kutchins 1988, 1992, ch. 9; Whooley 2010). Moreover, as is well documented, one of the major difficulties with the DSM's descriptive approach is the high incidence of co-morbid diagnoses (Kessler et al. 2005). In the context of actual clinical practices, one of the most useful DSM tools is the "not otherwise specified” (NOS) diagnosis, which indicates that a cluster of symptoms do not neatly fit any of the DSM's diagnostic categories, but allows individuals seeking treatment to receive a DSM diagnosis for purposes of medical insurance (Hyman 2010, pp. 166-167). Hence, rather than functioning as a useful guide that facilitates treatment decisions, the DSM functions - in practice - as an administrative constraint that clinicians must satisfy to ensure that patients are reimbursed for treatment.

\subsection{Theoretical Approaches}

Weaknesses of the DSM's descriptive approach are potential advantages of theoretical approaches to classification. The distinguishing feature of theoretical approaches is that its diagnostic categories would incorporate information about the causes of disorders. ${ }^{2} \mathrm{My}$ argument for a theoretical approach assumes that —as an ideal-the DSM should classify natural kinds. ${ }^{3}$ On this view, some mental disorders (e.g., schizophrenia, depression, bipolar disorder) are natural kinds insofar as they are classes of abnormal behavior associated with a distinctive biological causal structure. More specifically, some mental disorders are natural kinds

\footnotetext{
${ }^{2}$ It is important to note that theoretical approaches are compatible with descriptive approaches to psychiatric classification. Theoretical approaches are only incompatible with the purely descriptive (i.e., atheoretical) approach to classification associated with DSM-III (APA 1980).

${ }^{3}$ The question of whether the DSM intends to classify natural kinds is murky (cf. Cooper 2005; Tsou 2011). The DSM-III taskforce initially planned to include a statement in the introduction of DSM-III that stated that "mental disorders are a subset of medical disorders” (see Spitzer, Sheehy, \& Endicott 1977; Spitzer \& Endicott 1978), which would suggest that the DSM does aim to classify natural kinds (cf. APA 1980, p. 6). However, this statement was ultimately not included in DSM-III due to protests from psychologists, social workers, and counselors who regarded it as a declaration that psychiatrists - with medical training - were solely responsible for the treatment of mental disorders (Mayes \& Horowitz 2005).
} 
constituted by networks of identifiable biological mechanisms at multiple levels (e.g., molecular, developmental, neurobiological) that interact to produce the key features of the kind (see Kendler, Zachar, \& Craver 2011; Tsou 2012, 2013). ${ }^{4}$ The significance of this view is that the common biological causal structure captured by a natural kind term allows for projectable inductive inferences (i.e., predictions) to be made about members of a kind. ${ }^{5}$ This importantly includes inferences about the prognosis of a particular disorder and predictions regarding how an individual diagnosed with a disorder will respond to specific treatment interventions.

Compared to purely descriptive approaches, theoretical approaches would be superior for purposes of facilitating research. Currently the DSM guides research in a top-down manner by providing operational definitions of disorders, which researchers employ to select homogenous populations of patients to study. Given the high inter-rater reliability of DSM categories, this strategy is useful for ensuring that researchers working in different locales are studying mental disorders in a uniform manner. A fundamental problem with this approach, however, is that while the DSM's diagnostic categories are reliable, its categories lack validity (Kendell 1989; Kendell \& Jablensky 2003). ${ }^{6}$ A theoretical approach to classification could individuate disorders by etiology, rather than behaviorally, which would provide a more effective method for identifying valid diagnostic categories. As Dominic Murphy (2006) has argued, the DSM's purely descriptive approach offers an incoherent methodology for psychiatric classification insofar as it "requires us to assume that a significant difference can exist between individuals at the level of surface symptoms that does not reflect an underlying causal difference” (p. 324). From this perspective, the DSM's purely descriptive approach is highly costly insofar as the

\footnotetext{
${ }^{4}$ I assume that mechanisms are complex systems of entities and activities that are organized in a way to produce regular changes (see Bechtel \& Richardson, 1993; Glennan, 1996, 2002; Machamer, Darden, \& Craver, 2000; Craver \& Darden, 2001; Machamer, 2004; Tabery, 2004).

${ }^{5}$ For discussion of the projectability of natural kind terms, see Quine (1969), Goodman (1983), Boyd (1985, 1999, 2010), and Khalidi (2013).

${ }^{6}$ While there is no agreed upon concept of validity in psychiatry, valid diagnostic categories are generally understood as classifications that pick out real natural phenomena, i.e., categories that 'carve nature at the joints.' For a more comprehensive discussion of various proposed definitions of validity (e.g., construct and content validity), see Robins \& Guze (1970), Kendler (1990), Kendell \& Jablenksy (2003), First et al. (2004), Murphy (2006, ch. 6), Jablensky (2012), and Shaffner (2012). While some theorists have argued that validity is best understood in terms of utility, I assume that these concepts are distinct, although it is important to recognize that valid diagnostic categories will be predictively useful (i.e., projectable), but not necessarily vice versa. Given the importance of making reliable predictions in psychiatry (and the difficulty in evaluating more general ideals of validity), predictive validity is arguably the most useful concept of validity to employ in evaluating diagnostic categories (Shaffner 2012).
} 
manual functions - in practice - to reify and promote research on mental disorders (e.g., histrionic personality disorder, mathematics learning disorder) that may have no natural basis (Hyman 2010).

Theoretical approaches could also benefit research by providing a potentially testable and correctable system of psychiatric classification. The testability of theoretical approaches is an issue discussed by Carl Hempel in his classic analysis of psychiatric taxonomy (Hempel 1965). ${ }^{7}$ Hempel (1965) argues that:

[T]o be scientifically useful a concept must lend itself to the formulation of general laws or theoretical principles which reflect uniformities in the subject matter under study, and which thus provides a basis for explanation, prediction, and generally scientific understanding. This aspect of a set of scientific concepts will be called its systematic import, for it represents the contribution concepts make to the systematization of knowledge in the given field by means of laws or theories. (p. 146, emphasis added)

According to Hempel, scientific classification systems follow a regular progression. Initially, classification systems will aim to simply describe objects of classification with the aid of operational definitions. However, as the system evolves, it ought to develop into a theoretical system where increased emphasis is placed on "the attainment of comprehensive theoretical accounts of the empirical subject matter under discussion” (Hempel 1965, p. 140). In arguing for a theoretical system of psychiatric classification, Hempel suggests that psychiatric classification could resemble other taxonomic systems in science, such as classification systems in chemistry and biology (Hempel 1965, pp. 147-149; cf. Hacking 2013). Importantly, a theoretical system of classification could make predictions and be testable in ways that purely descriptive systems are not.

The potential testability of theoretical approaches is an issue that the DSM-5 taskforce emphasize in their own arguments for a shift away from the DSM's neo-Kraepelinian approach. Regier, Narrow, Kuhl, and Kupfer (2009) write:

\footnotetext{
${ }^{7}$ For a more comprehensive discussion of Hempel’s analysis, see Schwartz \& Wiggins (1986), Murphy (2006, ch. 6), Bolton (2008), and Tsou (2011). Some authors have suggested that Hempel's paper played an influential historical role in DSM-III's adoption of an operationalized and purely-descriptive approach (e.g., see Bolton 2008, p. 3). In this paper, I argue that Hempel's emphasis on the testability of theoretical taxonomic systems offers compelling support for contemporary arguments in favor of theoretical approaches to psychiatric classification.
} 
Mental disorder syndromes will eventually be redefined to reflect more useful diagnostic categories ('to carve nature at its joints') ... [O]ur immediate task is to set up a framework for an evolution of our diagnostic system that can advance our clinical practice and facilitate ongoing testing of the diagnostic criteria that are intended to be scientific hypotheses, rather than inerrant Biblical scripture. (pp. 648-649, emphasis added)

Implicit in this statement is the idea that the DSM can advance to a theoretical and etiological system better suited for testing the validity of diagnostic categories. The DSM's atheoretical and purely descriptive orientation, by contrast, has functioned in practice to protect its diagnostic categories from revision given that-without appeals to etiology — there is no systematic way of determining when a disorder should be retained, revised, or removed from the manual. This aspect of the DSM has led to a trend of proliferation of diagnostic categories since the publication of DSM-III, which some authors have regarded as a sign of scientific degeneration (e.g., see Follette \& Houts 1996; Houts \& Follette 1998; Houts 2001; Horwitz 2002; cf. Wakefield 1998, 1999, 2001).

A theoretical approach to classification would also be beneficial for providing a manual that guides treatment decisions. As argued above, an advantage of theoretical approaches is that they could individuate mental disorders on the basis of shared biological regularities. This would ensure that the DSM's diagnostic categories are projectable in the sense that clinicians can make successful inductive inferences about treatment. Without a clear theoretical basis for the DSM's diagnostic categories, there is no assurance that the DSM's behavioral definitions are projectable. Paul Meehl (1995) has criticized the DSM on these grounds, arguing that:

The advance-science medical model does not identify disease taxa with the operationally defined syndrome: the syndrome is taken as evidentiary, not as definitory. The explicit definition of a disease entity in non-psychiatric medicine is a conjunction of pathology and etiology and therefore applies to patients who are asymptomatic (which is why, e.g., one can have a silent brain tumor. . . ). Perhaps we cannot blame psychologists ignorant of medicine for making this mistake, when some psychiatrists who are passionate defenders of the DSM don't understand how far it deviates from the optimal medical model. (p. 267) 
As Meehl argues, psychiatric treatment would be better served by a theoretical and etiological approach to classification because it would incorporate information about the causes of disorders (also see Murphy 2006, pp. 324-326).

The main disadvantage of theoretical approaches is the potential compromise of the facilitation of communication and widespread usage of the DSM. Because the etiology of many mental disorders is unknown, theoretical approaches run the risk of introducing the kinds of speculative causal inferences that the authors of DSM-III sought to remove. However, while the shift to an atheoretical approach in DSM-III (APA 1980) — in the historical context of the 1970s — was justified because it helped to remove speculative psychoanalytic theories from the DSM, in our current situation, DSM's atheoretical stance has served to isolate the manual from the most promising scientific theories on psychopathology, including genetics, neurobiology, and the cognitive sciences (Murphy 2006, ch. 9; Hyman 2008; Insel et al. 2010; Sanislow et al. 2010). This criticism is particularly salient given that one of the intended roles of the DSM is to reflect the best current scientific findings on psychopathology. Moreover, a fundamental pragmatic difficulty with theoretical approaches is that it is difficult to accommodate different sciences. As Rachel Cooper (2005, ch. 3) has pointed out, a psychiatric classification system is only as good as the theory it is based on. From this perspective, a disadvantage of theoretical approaches to classification stems from the difficulty of choosing which theoretical sciences ought to be incorporated into a system of classification and the potential for excluding and marginalizing certain scientific theories. In the following section, I defend a hybrid approach to classification that recommends that the DSM's diagnostic categories are informed by the best available theories on the biological causes of disorders, while considering a plurality of competing theories. Compared to purely descriptive approaches, this (theoretical) hybrid approach would present an explicit basis for testing diagnostic categories and provide a more promising method for formulating valid diagnostic categories.

\section{DSM-5 and Beyond: Steps towards a Theoretical Approach to Classification}

In what follows, I argue that the DSM ought to shift to a theoretical approach to classifying mental disorders and offer some recommendations for meeting this ideal. The theoretical 
approach that I advocate primarily seeks to integrate theoretical information about the causes of mental disorders into the DSM's descriptive diagnostic categories (see note 2). This hybrid approach to psychiatric classification could accommodate the benefits of descriptive approaches (i.e., facilitating communication) and theoretical approaches (i.e., facilitating treatment and research), while avoiding the costs of both.

\subsection{The DSM as an Epistemic Hub}

One of the problems with the DSM is the ambitiousness of its aims. While the DSM aims to provide a manual that can simultaneously guide treatment, facilitate research, and improve communication, this stance fails to recognize that these aims will often conflict and that there are tradeoffs between how well descriptive and theoretical approaches can meet these goals. As a result, the DSM's purely descriptive approach has done well at improving communication among mental health professionals, but has only yielded minimal benefits for guiding treatment and facilitating research.

One way that the DSM could address this problem is to reconceive its aims in a more narrow manner. Rather than serving as a manual that is intended to guide treatment, facilitate research, and improve communication (with the facilitation of treatment regarded as its primary goal), the DSM should be reconceived as what Lara K. Keuck has called an epistemic hub (Kutschenko, 2011). Keuck argues that broadly applied medical classification systems that are used in different settings by a variety of actors — such as the DSM-ought to serve primarily as hubs that can mediate between these various practices (cf. Pincus 2012, pp. 157-158). In this manner, epistemic hubs are reference points that allow for the exchange of information and the integration of explanations among researchers, practicing clinicians, and other mental health professionals. As Keuck points out, because epistemic hubs are intended for widespread use in different contexts, they ought to primarily strive for connectivity with alternative descriptions of disorders, rather than precision per se. While the DSM does not represent an ideal epistemic hub because its diagnostic categories are defined at a level of precision unnecessary for purposes of coordinating various practices, the descriptive diagnostic categories of the DSM are well-suited 
for meeting the goal of providing a common point of reference that can coordinate among the various practices of mental health professionals. ${ }^{8}$

While I have argued that the DSM should be reconceived as an epistemic hub that facilitates communication, to be a useful epistemic hub that genuinely facilitates the exchange of information and integration of explanations, the DSM needs to provide definitions for valid diagnostic categories. If this requirement is met, then the DSM could more effectively meet its goals of providing a manual that is useful for guiding treatment and facilitating research. Without the provision of validated diagnostic categories, a high cost of the DSM is the potential reification of artificial kinds (e.g., narcissistic personality disorder, histrionic personality disorder), which have pernicious implications for both treatment and research. ${ }^{9}$ As argued in section 3 of this paper, the DSM ought to individuate and classify natural kinds associated with an identifiable biological basis, which would ensure that the DSM's diagnostic categories are projectable in the sense of yielding successful inductive inferences about members of a kind. In her analysis, Keuck downplays the importance of issues concerning validity, suggesting that epistemic hubs “cannot and should not be considered scientific taxonomies in Hempel's sense” (Kutschenko 2011, p. 585). Against this view, I maintain that in addition to functioning as an epistemic hub that facilitates communication, the DSM should also strive to provide validated diagnostic categories that are useful in contexts of treatment and research. ${ }^{10}$ For this goal to be met, the DSM's diagnostic categories ought to incorporate theoretical information about the causes of disorders.

\footnotetext{
${ }^{8}$ For this purpose, the dimensional measures introduced in DSM-5 (APA 2013) may be disadvantageous because they import an unnecessary level of specificity into definitions of mental disorders.

${ }^{9}$ In the human sciences, I assume that artificial kinds are classes that are useful for distinguishing a socially relevant group (e.g., 'liberals,' 'widows,' 'police officers'), but are not associated with a distinctive biological causal structure (see Tsou 2013). Some clear examples of artificial kinds listed in DSM-5 include histrionic personality disorder, dependent personality disorder, and voyeuristic disorder. There is meager evidence that the characteristic signs of these disorders are caused by identifiable biological mechanisms, and any biological regularities observed for these disorders are better accounted for at a more general level of analysis (e.g., in terms of anxiety or high testosterone levels).

${ }^{10}$ Keuck suggests that epistemic hubs and Hempelian scientific taxonomies are different insofar as "the latter strive for precision, whereas as the former need to uphold a certain degree of fuzziness in their descriptions ... in order to allow different actors to connect their more restrictive classification systems to the epistemic hub" (Kutschenko 2011, p. 585). However, there is no principled reason why the diagnostic categories of scientific taxonomies cannot be formulated at the level of generality required to serve as an epistemic hub.
} 


\subsection{The Integration of Causal Information}

If the DSM is understood as an epistemic hub that serves primarily to mediate between different contexts of use in which definitions of mental disorders occur, should the DSM adopt a purely descriptive (atheroretical) or theoretical approach? According to the analysis of this paper, there is no question that the DSM should move towards a theoretical approach. The most problematic aspect of the DSM's neo-Kraepelinian approach is the lack of validity of its categories and adopting a broadly theoretical approach would provide a more effective means for addressing this difficulty. The important question is not whether, but how theoretical information could be integrated into the DSM and on what basis its diagnostic categories could be revised.

The theoretical approach that I advocate would not necessarily include the causes of mental disorders in its diagnostic categories (cf. Hyman 2007); rather, it would incorporate information about causes by requiring — as an ideal—-that the operational symptoms that constitute the diagnostic criteria of a disorder are caused by identifiable biological mechanisms. According to this ideal, in order for a disorder to be included in the DSM, there needs to be evidence that there is a stable and distinctive biological causal structure for the classified disorder. This stance can accommodate the fact that scientists often do not have knowledge of the biological causes for many DSM disorders (e.g., bipolar disorder), although they have

evidence that these disorders possess a distinctive biological causal structure. However, the DSM's diagnostic categories ought to be refined over time such that the characteristic signs that define mental disorders are associated with identifiable biological causes.

As a concrete example of a diagnostic category that possesses some (predictive) validity, consider the DSM's definition of schizophrenia, which requires that two or more of the following symptoms must be present over a one-month period (APA 2013, pp. 99-100):

(1) Delusions

(2) Hallucinations

(3) Disorganized speech (e.g., frequent derailment or incoherence)

(4) Grossly disorganized or catatonic behavior

(5) Negative symptoms (i.e., diminished emotional expression or avolition)

At least one of the symptoms present must be (1), (2) or (3) 
The diagnostic criteria for the DSM's schizophrenia classification, while not ideal, are useful precisely because there are compelling theoretical reasons for thinking that these particular symptoms have identifiable causes. ${ }^{11}$ For example, neurobiological research indicates that delusions (1) and hallucinations (2) — the "positive symptoms" of schizophrenia—are caused by excessive dopamine activity in the mesolimbic pathway, while "negative symptoms" (5) are caused by deficient dopamine activity in the mesocortical pathway (see Tsou 2012). In this manner, the DSM's classification of schizophrenia represents a theoretically informed descriptive category. In connection with the ideal of epistemic hubs defended in this paper, the level of generality that the schizophrenia classification is described is useful because it can be coordinated with more specific descriptions of schizophrenia (e.g., paranoid or catatonic subtypes). Hyman (2007) suggests that a number of disorders listed in the DSM (e.g., schizophrenia, bipolar disorder, major depression, and obsessive-compulsive disorder) possess some validity and pick out natural phenomena because there is evidence for the heritability of these disorders and striking similarities in the symptoms of these disorders as they appear across cultures (p. 726). ${ }^{12}$ These disorders provide paradigm examples of disorders that should be included in the DSM, and the diagnostic criteria for these disorders should ideally include symptoms that are theorized to be caused by identifiable biological mechanisms. ${ }^{13}$

The hybrid approach to classification outlined herein can accommodate the advantages of purely descriptive and theoretical approaches. Because this approach would retain the DSM's descriptive approach, it would maintain the DSM's ability to facilitate communication and widespread use of the manual. In terms of the ideal of epistemic hubs defended in this paper,

\footnotetext{
${ }^{11}$ The DSM's diagnostic criteria for schizophrenia could be improved by including 'cognitive impairments' (e.g., deficits in attention, memory, and executive functioning), which are theorized to be caused by dopamine dysfunction in the prefrontal cortex (Hyman \& Fenton 2003). Similarly, I have argued that there are good theoretical reasons for including mental inflexibility ("cognitive rigidity") in the diagnostic criteria for depression because there is evidence that this cognitive trait, which is correlated with both depression and suicide ideation, is caused by deficient serotonin projections to the orbitofrontal cortex (Tsou 2013).

${ }^{12}$ I have elsewhere discussed the importance of cross-cultural research for helping to identify disorders that are natural kinds (Tsou 2007, 2013). On my view, the distinction between natural and artificial kinds is a distinction of a degree, and the symptoms of 'more natural' disorders (i.e., disorders whose characteristic signs are more directly determined by biological mechanisms) will exhibit greater uniformity across cultures (and over time) than artificial kinds.

${ }^{13}$ In this connection, more research efforts should be directed towards to validating proposed criterion sets of disorders by providing evidence that the cluster of signs included in these sets are caused by biological mechanisms (cf. Frances \& Widier 2012, pp. 118-120). For this purpose, cross-cultural research is a particularly useful resource for identifying the common cluster of symptoms associated with a disorder (see Kleinman 1988, chs. 2-3; Kendler 2009; Tsou 2007; cf. Cooper 2010).
} 
diagnostic criteria should be articulated at a level of generality that allows its categories to be compatible with alternative, more specific, descriptions of mental disorders. Integrating theoretical information about the causes of mental disorders into these categories, however, would provide a more effective method for providing validated diagnostic categories, which would be beneficial for guiding clinical treatment and facilitating research.

\subsection{Theoretical Pluralism and the Revision of DSM Categories}

As discussed in section 3 of this paper, one of the main disadvantages of theoretical approaches is the difficulty of accommodating different, and sometimes incompatible, theories of psychopathology. Theoretical pluralism is a promising methodological means for overcoming this difficulty. In philosophy of science, proponents of pluralism (e.g., see Feyerabend 1975; Suppes 1978; Dupré 1993; Longino 1990, 2001; Mitchell 2003; Giere 2006; Kellert, Longino, \& Waters 2006) argue that-because of the theory-ladenness of scientific observation (Hanson 1958; Kuhn 1962) — a plurality of inconsistent, and sometimes mutually incompatible, scientific theories are required to obtain an adequate understanding of scientific phenomena. For example, Paul Feyerabend (1965) contends that:

Not only is the description of every single fact dependent on some theory . . . but there also exist facts that cannot be unearthed except with the help of alternatives to the theory to be tested and that become unavailable as soon as such alternatives are excluded. This suggests that the methodological unit to which we must refer when discussing questions of test and empirical content is constituted by a whole set of partly overlapping, factually adequate, but mutually inconsistent theories . . . it suggests a theoretical pluralism as the basis of every test procedure. (p. 175, emphasis in original)

Feyerabend maintains that if the description of scientific facts is theory-dependent, then there are facts relevant to the validity of a theory that cannot be revealed except with alternatives to the theory being tested. On this view, theoretical pluralism is virtuous because alternative theories can serve as criticisms of currently accepted theories that cannot be obtained in other ways (Feyerabend 1965, p. 150). ${ }^{14}$ With respect to how the DSM's diagnostic categories should be

\footnotetext{
${ }^{14}$ I have elsewhere discussed the importance of Feyerabend's views on pluralism (Tsou 2003).
} 
revised to incorporate theoretical information, the kind of theoretical pluralism advocated by Feyerabend could provide an effective means for avoiding theoretical dogmatism.

In order for the DSM to incorporate theoretical information about its diagnostic categories in a fruitful manner, a plurality of theories should be represented in the DSM revision process. Much disgruntlement surrounding the revision of the DSM in the past resulted from the exclusion of individuals with divergent theoretical views (Sadler 2005, ch. 3), and the DSM would benefit by broadening the theoretical perspectives represented by experts involved in the DSM revision process (Frances \& Widiger 2012). Similarly, the critical review of proposed revisions to the DSM could be improved by soliciting literature reviews from people working outside of the DSM revision process, especially from reviewers who are likely to be critical of proposals (Widiger \& Clark 2000; Frances \& Widiger 2012). ${ }^{15}$ Finally, the ideal of pluralism could be better approached in the field testing of proposed criterion sets, which currently is limited to pilot studies in artificial research settings (Frances \& Widiger 2012). At minimum, some field testing should be conducted in clinical settings and criticism of proposed criterion sets should come from practicing clinicians adopting diverse theoretical orientations.

In addition to pluralism in the DSM revision process, the DSM could benefit from pluralism at the taxonomic level (Kutschenko 2011). Given that there are multiple purposes for classifying mental disorders, researchers and clinicians should develop alternative classification systems that can simultaneously serve to inform (and potentially criticize) the DSM's diagnostic categories. One example of such an alternative is the Research Domain Criteria (RDoC) classification system being introduced by the National Institute of Mental Health (NIMH). The $\mathrm{RDoC}$ is an explicitly theoretical system of classification intended primarily for facilitating research. ${ }^{16}$ While the RDoC was initially formulated as a competing system of classification to the DSM—due to dissatisfaction with the lack of validity of DSM diagnostic categories (Insel et

\footnotetext{
${ }^{15}$ While I have argued that disorders included in the DSM should have a clear biological basis, the theories that are employed to criticize existing diagnostic categories ought to represent a wide-spectrum of views, including psychoanalytic, humanistic, and social psychological perspectives. These alternative perspectives could help to clarify which particular symptoms of disorders lack a natural basis and shed light on other mechanisms relevant for the expression of disorders.

${ }^{16}$ As indicated in the Research Domain Criteria Matrix (see Morris \& Cuthbert 2012, p. 31), the RDoC seeks to organize research by distinguishing seven units of analysis (viz., genes, molecules, cells, circuits, physiology, behavior, self-reports, and paradigms) and five research domains (viz., negative valence emotional systems, positive valence emotional systems, cognitive systems, systems for social processes, and arousal/ regulatory systems).
} 
al. 2010) — the NIMH and APA have taken a more collaborative stance recently. The NIMH and APA issued a joint press release on May 13, 2013, which stated the following:

All medical disciplines advance through research progress in characterizing diseases and disorders. DSM-5 and RDoC represent complementary, not competing, frameworks for this goal. DSM-5 . . reflects the scientific progress seen since the manual's last edition was published in 1994. RDoC is a new, comprehensive effort to redefine the research agenda for mental illness. As research findings begin to emerge from the RDoC effort, these findings may be incorporated into future DSM revisions and clinical practice guidelines. But this is a long-term undertaking. It will take years to fulfill the promise that this research effort represents for transforming the diagnosis and treatment of mental disorders. (Insel \& Leiberman, 2013, emphasis added)

This collaborative effort between the APA and NIMH provides an instructive example of how the DSM could be coordinated with and informed by alternative classification systems, which could help to incorporate theoretical information about the causes of disorders into the DSM's diagnostic categories. ${ }^{17}$

A legitimate worry about adopting a theoretical approach to classification is the possibility of theoretical dogmatism. I have suggested that theoretical pluralism provides a methodological prescription that could alleviate this problem. Whereas theoretical pluralism is the norm within research on psychopathology, the ideal of pluralism is inadequately met in the DSM revision process. The DSM could also benefit by being forced to coordinate itself against a plurality of more specifically formulated classification systems, such as the RDoC, CFTMEA (Misés \& Quemada 2002), and OPD (OPD Task Force 2008). Unfortunately, there are few alternative psychiatric classification systems that have been formulated for specific purposes (e.g., treatment manuals); undoubtedly, part of this problem is due to the current hegemonic status of the DSM. However, the development of alternative classification systems might provide the most promising types of interactions that could result in innovative revisions to the DSM.

\section{Conclusion}

\footnotetext{
${ }^{17}$ Moreover, the efforts of the RDoC may ultimately serve to drastically revise our understanding of what the proper targets of validation are given that the RDoC will explore new ways of classifying mental disorders that do not rely on DSM diagnostic categories (Sanislow et al. 2010; Morris \& Cuthbert 2012; Tabb forthcoming).
} 
In this paper, I argued that the DSM should adopt a theoretical approach to classification that incorporates information about the causes of mental disorders. The particular approach that I favor retains the DSM's descriptive categories, but integrates theoretical information about the causes of disorders into its categories. This hybrid approach would aim to classify mental disorders with a clear natural (biological) basis and ensure that the diagnostic criteria that define mental disorders have identifiable (or hypothesized) biological causes. Compared to purely descriptive approaches, the main benefits of this approach is that it would: (1) provide a methodological basis for formulating valid and projectable diagnostic categories, (2) offer an explicit basis for deciding when disorders ought to be included or excluded from the DSM, and (3) engage the DSM more closely with a large body of scientific research on psychopathology. On a more general level, I suggested that the DSM could usefully be reconceived of as an epistemic hub that serves to mediate among various contexts of use in which definitions of mental disorders appear. From this perspective, the diagnostic categories of the DSM ought to be defined at a level of generality that permits the manual to be coordinated with alternative descriptions of mental disorders.

While I have characterized the shift towards a theoretical approach to classification as psychiatry’s “second revolution,” I envisage this shift as a gradual and iterative process. Kendler and First (2010) have urged that the DSM is not ready for a paradigm shift wherein the DSM's purely descriptive approach is jettisoned in favor of an etiological and theoretical approach. Others have stressed the importance of conservatism in revising future editions of the DSM (Frances \& Widiger 2012). I am sympathetic to these concerns, and the ideal of classification advanced in this paper can accommodate these worries. Because the theoretical approach that I advocate retains the DSM's descriptive approach to classifying mental disorders, theoretical information about the causes of the signs of mental disorders could be incorporated in the DSM's existing diagnostic categories in a gradual and piecemeal fashion. When there is uncertainty regarding the validity or causes of a disorder, my favored approach would recommend retaining the status quo until there are compelling theoretical reasons for making revisions. Regardless of whether the theoretical approach that I advocate would constitute a paradigm-shifting revolution in the classification of mental disorders, it would mark a significant point of scientific progress by supplanting the DSM’s antiquated neo-Kraepelinian approach. 


\section{Acknowledgements:}

I owe thanks to Ian Hacking, Bill Wimsatt, Robert Richards, Trevor Pearce, Lara Keuck, Kathryn Tabb, Doreen Fraser, Tim Kenyon, John Koolage, Judy Segal, Alan Richardson, Sylvia Berryman, Scott Edgar, Robyn Bluhm, Trey Boone, Jacqueline Sullivan, David Stump, Martin Davidson, Sacha Ludgate, Steeves Demazeux, Patrick Singy, and two anonymous reviewers for helpful comments and discussion. Earlier versions of this paper were presented at the Science and Society Speaker Series at the University of British Columbia in January 2009 and the fourth biennial conference of the Society for Philosophy of Science in Practice (SPSP) at the University of Toronto in June 2013; I am grateful for feedback that I received on those occasions.

\section{References}

APA (1952). Diagnostic and statistical manual: Mental disorders. Washington, DC: American Psychiatric Association.

APA (1968). Diagnostic and statistical manual of mental disorders, second edition: DSM-II. Washington, DC: American Psychiatric Association.

APA (1980). Diagnostic and statistical manual of mental disorders, third edition: DSM-III. Washington, DC: American Psychiatric Association.

APA (2000). Diagnostic and statistical manual of mental disorders, fourth edition text revision: DSM-IV-TR. Washington, DC: American Psychiatric Association. APA (2013). Diagnostic and statistical manual of mental disorders, fifth edition: DSM-5. Washington, DC: American Psychiatric Association.

Bechtel, William, \& Richardson, Robert C. (1993). Discovering complexity: Decomposition and localization as strategies in scientific research. Princeton, NJ: Princeton University Press. 
Blashfield, Roger K. (1984). The classification of psychopathology: Neo-Kraepelinian and quantitative approaches. New York: Plenum Press.

Bolton, Derek (2008). What is mental disorder? An essay in philosophy, science, and values. Oxford: Oxford University Press.

Boyd, Richard (1985). Observations, explanatory power, and simplicity: Toward a non-Humean account. In Peter Achinstein \& Owen Hannaway (Eds.), Observation, experiment, and hypothesis in modern physical science (pp. 47-94). Cambridge, MA: MIT Press.

Boyd, Richard (1999). Homeostasis, species, and higher taxa. In Robert A. Wilson (Ed.), Species: New interdisciplinary essays (pp. 141-185). Cambridge, MA: MIT Press.

Boyd, Richard (2010). Realism, natural kinds, and philosophical methods. In Helen Beebee \& Nick Sabbarton-Leary (Eds.), The semantics and metaphysics of natural kinds (pp. 212234). New York: Routledge.

Brown, Phil (1987). Diagnostic conflict and contradiction in psychiatry. Journal of Health and Social Behavior, 28(1): 37-50.

Compton, Wilson M., \& Guze, Samuel B. (1995). The neo-Kraepelinian revolution in psychiatric diagnosis. European Archives of Psychiatric and Clinical Neuroscience, 245(4-5): 196201.

Cooper, Rachel (2005). Classifying madness: A philosophical examination of the Diagnostic and Statistical Manual of Mental Disorders. Dordrecht: Springer.

Cooper, Rachel (2010). Are culture-bound syndromes as real as universally occurring disorders? Studies in History and Philosophy of Biological and Biomedical Sciences, 41(4): 325332.

Craver, Carl F., \& Darden, Lindley (2001). Discovering mechanisms in neurobiology: The case 
of spatial memory. In Peter K. Machamer, Rick Grush, \& Peter McGlaughlin (Eds.), Theory and method in the neurosciences (pp. 112-137). Pittsburgh, PA: University of Pittsburgh Press.

Decker, Hannah S. (2007). How Kraepelinian was Kraepelin? How Kraepelinian are the neoKraepelinians? - from Emil Kraepelin to DSM-III. History of Psychiatry, 18(3): 337-360.

Decker, Hannah S. (2013). The making of DSM-III: A diagnostic manual's conquest of American psychiatry. Oxford: Oxford University Press.

Dupré, John (1993). The disorder of things: Metaphysical foundations of the disunity of science. Cambridge, MA: Harvard University Press.

Feyerabend, Paul K. (1965). Problems of empiricism. In Robert G. Colodny (Ed.), Beyond the edge of certainty: Essays in contemporary science and philosophy (pp. 145-260). Englewood Cliffs, NJ: Prentice-Hall.

Feyerabend, Paul K. (1975). Against method: Outline of an anarchistic theory of knowledge. London: New Left Books.

First, Michael B., Pincus, Harold Alan, Levine, John B., Williams, Janet B. W., Ustun, Bedirhan, \& Peele, Roger (2004). Clinical utility as a criterion for revising psychiatric diagnoses. American Journal of Psychiatry, 161(6): 946-954.

Follette, William C., \& Houts, Arthur C. (1996). Models of scientific progress and the role of theory in taxonomic development: A case study of the DSM. Journal of Consulting and Clinical Psychology, 64(6): 1120-1132.

Frances, Allen J., \& Widiger, Thomas (2012). Psychiatric diagnosis: Lessons from the DSM-IV past and cautions for the DSM future. Annual Review of Clinical Psychology, 8: 109-130.

Giere, Ronald N. (2006). Scientific perspectivism. Chicago: University of Chicago Press.

Glennan, Stuart S. (1996). Mechanisms and the nature of causation. Erkenntnis, 44(1): 49-71. 
Glennan, Stuart (2002). Rethinking mechanistic explanation. Philosophy of Science, 69(S3): S342-S353.

Goodman, N. (1983). Fact, fiction, and forecast (4th ed.). Cambridge, MA: Harvard University Press.

Hacking, Ian (2013). Lost in the forest. Review of DSM-5: Diagnostic and Statistical Manual of Mental Disorders, fifth edition by the American Psychiatric Association. London Review of Books, 35(15): 7-8.

Hanson, Norwood R. (1958). Patterns of discovery. Cambridge: Cambridge University Press.

Hempel, Carl G. (1965). Fundamentals of taxonomy. In Carl G. Hempel, Aspects of scientific explanation and other essays in the philosophy of science (pp. 137-154). New York: The Free Press.

Horwitz, Allan V. (2002). Creating mental illness. Chicago: University of Chicago Press.

Houts, Arthur C. (2001). The diagnostic and statistical manual's new white coat and circularity of plausible dysfunctions: Response to Wakefield, part 1. Behavior Research and Therapy, 39(3): 315-345.

Houts, Arthur C., \& Follette, William C. (1998). Mentalism, mechanisms, and medical analogues: Reply to Wakefield (1998). Journal of Consulting and Clinical Psychology, 66(5): 853-855.

Hyman, Steven E. (2007). Can neuroscience be integrated into the DSM-V? Nature Reviews Neuroscience, 8(9): 725-732.

Hyman, Steven E. (2010). The diagnosis of mental disorders: The problem of reification. Annual Review of Clinical Psychology, 6: 155-179.

Hyman, Steven E., \& Fenton, Wayne S. (2003). What are the right targets for 
psychopharmacology? Science, 299(5605): 350-351.

Insel, Thomas, Cuthbert, Bruce, Garvey, Marjorie, Heinssen, Robert, Pine, Daniel S., Quinn, Kevin, Sanislow, Charles, \& Wang, Philip (2010). Research Domain Criteria (RDoC): Toward a new classification framework for research on mental disorders. American Journal of Psychiatry, 167(7): 748-751.

Insel, Thomas R., \& Lieberman, Jeffrey A. (2013, May 13). DSM-5 and RDoC: Shared interests. Joint press release by the National Institute of Mental Health and the American Psychiatric Association. http://www.nimh.nih.gov/news/science-news/2013/dsm-5-and-rdoc-shared-interests.shtml

Jablenksy, Assen (2012). The nosological entity in psychiatry: A historical illusion or a moving target? In Kenneth S. Kendler \& Josef Parnas (Eds.), Philosophical issues in psychiatry II: Nosology (pp. 77-94). Oxford: Oxford University Press.

Kellert, Stephen H., Longino, Helen E., \& Waters, C. Kenneth (Eds.) (2006). Scientific pluralism: Minnesota studies in the philosophy of science, vol. 19. Minneapolis, MN: University of Minnesota Press.

Kendell, R. E. (1989). Clinical validity. Psychological Medicine, 19(1): 45-55.

Kendell, Robert, \& Jablensky, Assen (2003). Distinguishing between the validity and utility of psychiatric diagnoses. American Journal of Psychiatry, 160(1): 4-12.

Kendler, Kenneth S. (1990). Toward a scientific psychiatric nosology: Strengths and limitations. Archives of General Psychiatry, 47(10): 969-973.

Kendler, K. S. (2009). An historical framework for psychiatric nosology. Psychological Medicine, 39(12): 1935-1941.

Kendler, Kenneth S., \& First, Michael B. (2010). Alternative futures for the DSM revision process: Iteration v. paradigm shift. British Journal of Psychiatry, 197(4): 263-265. 
Kendler, K. S., Zachar, P., \& Craver, C. (2011). What kinds of things are psychiatric disorders? Psychological Medicine, 41(6): 1143-1150.

Kessler, Ronald C., Chiu, Wai Tat, Demler, Olga, Walters, Ellen E. (2005). Prevalence, severity, and comorbidity of 12-month DSM-IV disorders in the National Comorbidity Survey Replication. Archives of General Psychiatry, 62(7): 617-627.

Khalidi, Muhammad Ali (2013). Natural categories and human kinds: Classification in the natural and social sciences. Cambridge: University of Cambridge Press.

Kirk, Stuart A., \& Kutchins, Herb (1988). Deliberate misdiagnosis in mental health practice. Social Service Review, 62(2): 225-237.

Kirk, Stuart A., \& Kutchins, Herb (1992). The selling of DSM: The rhetoric of science in psychiatry. New York: Aldine de Gruyter.

Kleinman, Arthur (1988). Rethinking psychiatry: From cultural category to personal experience. New York: The Free Press.

Klerman, Gerald L. (1978). The evolution of scientific nosology. In John C. Shershow (Ed.), Schizophrenia: Science and practice (pp. 99-121). Cambridge, MA: Harvard University Press.

Kuhn, Thomas S. (1962). The structure of scientific revolutions. Chicago: University of Chicago Press.

Kupfer, David J., First, Michael B., \& Regier, Darrel A. (2002). Introduction. In David J. Kupfer, Michael B. First, \& Darrel A. Regier (Eds.), A research agenda for DSM-V (pp. xv-xxiii). Washington, DC: American Psychiatric Association.

Kupfer, David J., Kuhl, Emily A., \& Regier, Darrel A. (2013). DSM-5-the future arrived. Journal of the American Medical Association, 309(16): 1691-1692. 
Kupfer, David J., \& Regier, Darrel A. (2011). Neuroscience, clinical evidence, and the future of psychiatric classification in DSM-5. American Journal of Psychiatry, 168(7): 672-674.

Kutschenko, Lara K. (2011). How to make sense of broadly applied medical classification systems: Introducing epistemic hubs. History and Philosophy of the Life Sciences, 33(4): 583-602.

Longino, Helen E. (1990). Science as social knowledge: Values and objectivity in scientific inquiry. Princeton, NJ: Princeton University Press.

Longino, Helen E. (2002). The fate of knowledge. Princeton, NJ: Princeton University Press.

Machamer, Peter (2004). Activities and causation: The metaphysics and epistemology of mechanisms. International Studies in the Philosophy of Science, 18(1): 27-39.

Machamer, Peter, Darden, Lindley, \& Craver, Carl F. (2000). Thinking about mechanisms. Philosophy of Science, 67(1): 1-25.

Mayes, Rick, \& Horwitz, Allan V. (2005). DSM-III and the revolution in the classification of mental illness. Journal of the History of the Behavioral Sciences, 41(3): 249-267.

Meehl, Paul E. (1995). Bootstrap taxometrics: Solving the classification problem in psychopathology. American Psychologist, 50(4): 266-275.

Misés Roger, \& Quemada, Nicole (2002) Classification Française des troubles mentaux de l'enfant et de l'adolescent: R-2000. Paris: CTNERHI Éditions.

Mitchell, Sandra D. (2003). Biological complexity and integrative pluralism. Cambridge: Cambridge University Press.

Morris, Sarah E., \& Cuthbert, Bruce N. (2012). Research domain criteria: Cognitive systems, neural circuits, and dimensions of behavior. Dialogues in Clinical Neuroscience, 14(1): 29-37.

Murphy, Dominic (2006). Psychiatry in the scientific image. Cambridge, MA: MIT Press. OPD Task Force (eds.), (2008). Operationalized Psychodynamic Diagnosis OPD-2: Manual of 
Diagnosis and Treatment. Cambridge, MA: Hogrefe \& Huber Publishers.

Pincus, Harold Alan (2012). DSM-IV: Context, concepts and controversies. In Kenneth S.

Kendler \& Josef Parnas (Eds.), Philosophical issues in psychiatry II: Nosology (pp. 145160). Oxford: Oxford University Press.

Quine,W. V. (1969). Natural kinds. In W. V. Quine, Ontological relativity and other essays (pp. 114-138). New York: Columbia University Press.

Regier, Darrel A. (2008). Forward: Dimensional approaches to psychiatric classification. In John E. Helzer, Helena Chmura Kraemer, Robert F. Krueger, Hans-Ulrich Wittchen, Paul J. Sirovatka, \& Darrel A. Regier (Eds.), Dimensional approaches in diagnostic classification: Refining the research agenda for $D S M-V$ (pp. xvii-xxiii). Washington, DC: American Psychiatric Association.

Regier, Darrel A., Narrow, William E., Kuhl, Emily A., \& Kupfer, David J. (2009). The conceptual development of DSM-V. American Journal of Psychiatry 166(6): 645-650.

Robins, Eli, \& Guze, Samuel B. (1970). Establishment of diagnostic validity in psychiatric illness: Its application to schizophrenia. American Journal of Psychiatry 126(7): 983-987.

Sadler, John Z. (2005). Values and psychiatric diagnosis. Oxford: Oxford University Press. Sadler, John Z. (2013). Considering the economy of DSM alternatives. In Joel Paris \& James Phillips (Eds.), Making the DSM-5: Concepts and controversies (pp. 21-38). New York: Springer.

Sanislow, Charles A., Pine, Daniel S., Quinn, Kevin J., Kozak, Michael J., Garvey, Marjorie A., Heinssen, Robert K., Wang, Philip Sung-En, \& Cuthbert, Bruce N. (2010). Developing constructs for psychopathology research: Research domain criteria. Journal of Abnormal Psychology, 119(4): 631-639.

Shaffner, Kenneth F. (2012). A philosophical overview of the problems of validity for 
psychiatric disorders. In Kenneth S. Kendler \& Josef Parnas (Eds.), Philosophical issues in psychiatry II: Nosology (pp. 169-189). Oxford: Oxford University Press.

Spitzer, Robert L., \& Endicott, Jean (1978). Medical and mental disorder: Proposed definition and criteria. In Robert L. Spitzer \& Donald F. Klein (eds.), Critical issues in psychiatric diagnosis (pp. 15-39). New York: Raven Press.

Spitzer, Robert L., Sheehy, Michael, \& Endicott, Jean (1977). DSM-III: Guiding principles. In Vivian M. Rakoff, Harvey C. Stancer, \& Henry B. Kedward (eds.), Psychiatric diagnosis (pp. 1-24). New York: Brunner/ Mazel.

Suppes, Patrick (1978). The plurality of science. In Peter Asquith \& Ian Hacking (Eds.), PSA 1978: Proceedings of the 1978 biennial meeting of the Philosophy of Science Association, vol. 2 (pp. 3-16). East Lansing, MI: Philosophy of Science Association.

Schwartz, Michael Alan, \& Wiggins, Osborne P. (1986). Logical empiricism and psychiatric classification. Comprehensive Psychiatry, 27(2): 101-114.

Tabb, Kathryn (forthcoming). Psychiatric progress and the assumption of diagnostic discrimination. Philosophy of Science.

Tabery, James G. (2004). Synthesizing activities and interactions in the concept of a mechanism. Philosophy of Science, 71(1), 1-15.

Tsou, Jonathan Y. (2003). Reconsidering Feyerabend's ‘Anarchism.' Perspectives in Science, 11(2): 208-235.

Tsou, Jonathan Y. (2007). Hacking on the looping effects of psychiatric classifications: What is an interactive and indifferent kind? International Studies in the Philosophy of Science, 21(3): 446-470.

Tsou, Jonathan Y. (2011). The importance of history for philosophy of psychiatry: The case of the DSM and psychiatric classification. Journal of the Philosophy of History, 5(3): 446470. 
Tsou, Jonathan Y. (2012). Intervention, causal reasoning, and the neurobiology of mental disorders: Pharmacological drugs as experimental instruments. Studies in History and Philosophy of Biological and Biomedical Sciences, 43(2): 542-551.

Tsou, Jonathan Y. (2013). Depression and suicide are natural kinds: Implications for physicianassisted suicide. International Journal of Law and Psychiatry, 36 (56): 461-470.

Wakefield, Jerome C. (1998). The DSM's theory-neutral nosology is scientifically progressive: Response to Follette and Houts (1996). Journal of Consulting and Clinical Psychology, 66(5): 846-852.

Wakefield, Jerome C. (1999). Philosophy of science and the progressiveness of the DSM's theory-neutral nosology: Response to Follette and Houts, part 1. Behavior Research and Therapy, 37(10): 1001-1027.

Wakefield, Jerome C. (2001). The myth of DSM's invention of new categories of disorder: Hout's diagnostic discontinuity thesis disconfirmed. Behavior Research and Therapy, 39(5): 575-624.

Whooley, Owen (2010). Diagnostic ambivalence: Psychiatric workarounds and the Diagnostic and Statistical Manual of Mental Disorders. Sociology of Health \& Illness, 32(3): 452469.

Widiger, Thomas A., \& Clark, Lee Anna (2000). Toward DSM-V and the classification of psychopathology. Psychological Bulletin, 126(6): 946-963.

Wilson, Mitchell (1993). DSM-III and the transformation of American psychiatry: A history. American Journal of Psychiatry, 150(3): 399-410. 